\title{
Epicardial beating heart cryoablation using a novel argon-based cryoclamp and linear probe
}

\author{
Federico Milla, MD, a Nikolaos Skubas, MD, ${ }^{b}$ William M. Briggs, MS, PhD, ${ }^{c}$ Leonard N. Girardi, MD, ${ }^{a}$ \\ Leonard Y. Lee, MD, ${ }^{a}$ Wilson Ko, MD, ${ }^{a}$ Anthony J. Tortolani, MD, ${ }^{a}$ Karl H. Krieger, MD, ${ }^{a}$ O. Wayne Isom, MD, \\ and Charles A. Mack, MDa
}

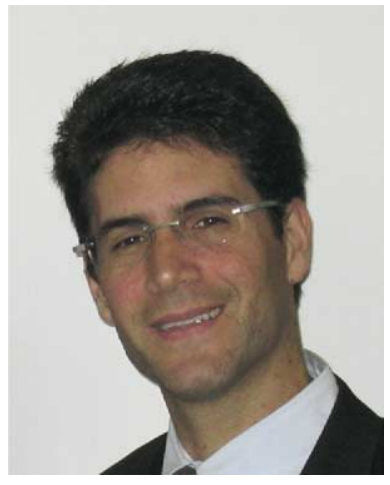

Dr Milla

From New York Presbyterian Hospital-Weill Cornell Medical Center, Departments of Cardiothoracic Surgery, ${ }^{\mathrm{a}}$ Anesthesiology, ${ }^{\mathrm{b}}$ and Medicine, ${ }^{\mathrm{c}}$ New York, NY.

This study was funded by CryoCath Technologies, Inc.

Read at the Thirty-first Annual Meeting of The Western Thoracic Surgical Association, Victoria, BC, Canada, June 22-25, 2005.

Received for publication June 16, 2005; revisions received Oct 18, 2005; accepted for publication Oct 28, 2005.

Accepted for publication Oct 28, 2005.

Address for reprints: Charles A. Mack, MD, Department of Cardiothoracic Surgery New York-Presbyterian Hospital, Weill Cornell Medical College, M404, 525 East 68th St, New York, NY 10021 (E-mail: cmack@med.cornell.edu).

J Thorac Cardiovasc Surg 2006;131:403-11 0022-5223/\$32.00

Copyright (C) 2006 by The American Association for Thoracic Surgery

doi:10.1016/j.jtcvs.2005.10.048
Objective: Epicardial, beating heart cryoablation for the treatment of atrial fibrillation may be limited by heat from intracardiac blood flow. We therefore evaluated the ability to create cryolesions using an argon-based cryoclamp device, which temporarily occludes blood flow and facilitates transmurality.

Methods: Six mongrel dogs underwent sternotomy. A clamp employing a 10-cm argon-based linear cryoablation device was used epicardially to isolate the pulmonary veins and left atrial appendage. After clamping of lesions, the probe was removed from the cryoclamp device, and the remaining linear lesions, analogous to the Cox maze III, were performed. Pulmonary vein stenosis was evaluated with the use of magnetic resonance imaging. Left atrial function and pulmonary venous flow velocities were assessed with transesophageal echocardiography. Transmurality was confirmed both electrically and histologically. Animals were then put to death at 30 days.

Results: All acute and chronic cryoclamp lesions produced conduction block. There was no change in right (RPV) or left pulmonary vein (LPV) diameter on the basis of magnetic resonance imaging at baseline and at planned death (RPV-1, 19.6 \pm 2.9 $\mathrm{mm}$ vs $16.9 \pm 2.8 \mathrm{~mm}, P=.22 ; \mathrm{RPV}-2,13.2 \pm 2.0 \mathrm{~mm}$ vs $11.8 \pm 1.6 \mathrm{~mm}, P=$ .22 ; and LPV, $12.2 \pm 2.4 \mathrm{~mm}$ vs $11.2 \pm 1.9 \mathrm{~mm}, P=.30$ ). Left atrial function and pulmonary venous flow velocities were unchanged. Tissue sections determined transmurality in $93 \%$ of cryoclamp lesions and $84 \%$ of linear ablations performed with the 10-cm malleable probe.

Conclusions: Epicardial application of this cryoclamp device on the beating heart produced transmural lesions, which persisted 30 days. Linear epicardial cryoablation was not as effective as the cryoclamp device at producing consistent transmural lesions. This novel, versatile device may be useful in treating patients with atrial fibrillation on the beating heart without cardiopulmonary bypass.

A trial fibrillation (AF) is present in $1 \%$ of the general population, affecting over 2 million people in the United States. ${ }^{1}$ The prevalence of this arrhythmia has been increasing as the population ages, afflicting nearly $10 \%$ of patients older than 80 years. ${ }^{2} \mathrm{AF}$ is associated with significant morbidity through its compromise of cardiac hemodynamics and increased risk of thromboembolic events. The Cox maze III procedure was described by Cox and associates ${ }^{3}$ in 1991 and is considered the gold standard for the surgical treatment of AF. The procedure involves a "cut-and-sew" technique, which is thought to direct reentrant circuits into dead ends while allowing the normal propagation of sinoatrial stimuli. The longterm success of the Cox maze III is well established with $96.6 \%$ freedom from AF at a mean follow-up of 5.4 years. ${ }^{4}$ Despite the success of the Cox maze III with regard to restoring sinus rhythm and preventing strokes and anticoagulant-related 

Abbreviations and Acronyms
$\mathrm{AF}=$ atrial fibrillation
$\mathrm{CS}=$ coronary sinus
IVC = inferior vena cava
LA $=$ left atrium
LAA $=$ left atrial appendage
$\mathrm{LPV}=$ left pulmonary vein
$\mathrm{PV}=$ pulmonary vein
RA = right atrium
$\mathrm{RAA}=$ right atrial appendage
$\mathrm{RPV}=$ right pulmonary vein
SVC $=$ superior vena cava
TEE $=$ transesophageal echocardiography

bleeding, it failed to gain widespread use, largely because of its complexity, prolonged cardiopulmonary bypass time, increased risk of bleeding from multiple suture lines, and overall increased morbidity. ${ }^{5}$

As a means of avoiding the morbidity of the cut-and-sew technique, new ablative devices that use cryo, radiofrequency, microwave, ultrasound, and laser energy to block these reentrant circuits have been established. Cryoablation employs freezing to ablate tissue by forming intracellular ice crystals. These ice crystals irreversibly damage organelles leading to cell death once the tissue has thawed. ${ }^{6}$ Argon-based cryo- thermy has been used to create endocardial lesions on the arrested heart in patients with AF during concomitant cardiac procedures. ${ }^{7,8}$ However, the ability to create transmural epicardial cryolesions on the beating heart may be limited by the heat from intracardiac blood flow. In this study, a novel, 10-cm, argon-based cryoprobe and cryoclamp device, which can reach temperatures of $-160^{\circ} \mathrm{C}$, was evaluated in an off-pump beating heart canine model, to determine whether both the clamp device and the linear probe are able to produce transmural lesions without causing pulmonary vein stenosis or left atrial (LA) dysfunction.

\section{Materials and Methods Study Design}

All procedures were done with the approval of the Institutional Animal Care and Use Committee (IACUC) of Weill Medical College of Cornell University. The dogs received humane care in compliance with the "Guide for the Care and Use of Laboratory Animals" published by the National Institutes of Health (NIH Publication No. 85-23, revised 1996). The funding agency did not participate in data interpretation. This study consisted of 6 adult mongrel dogs with a mean age of 14.6 months and weight of 25 to $30 \mathrm{~kg}$. All dogs underwent a preoperative transesophageal echocardiogram (TEE) to assess baseline LA function and pulmonary vein (PV) flow velocities. In addition, preoperative cardiac-gated magnetic resonance imaging (MRI) was performed to image the PVs. On the night before surgery, the dogs were started on an oral carprofen regimen $\left(4.4 \mathrm{mg} \cdot \mathrm{kg}^{-1} \cdot \mathrm{d}^{-1}\right)$, which continued until

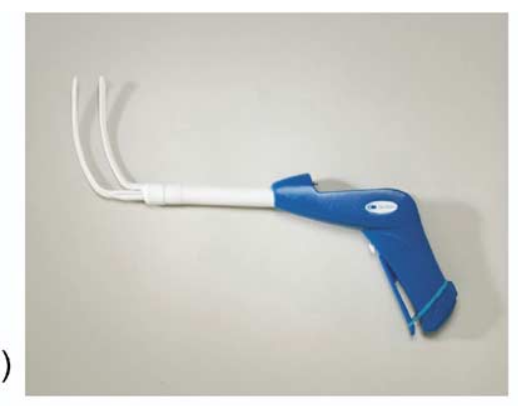

(b)

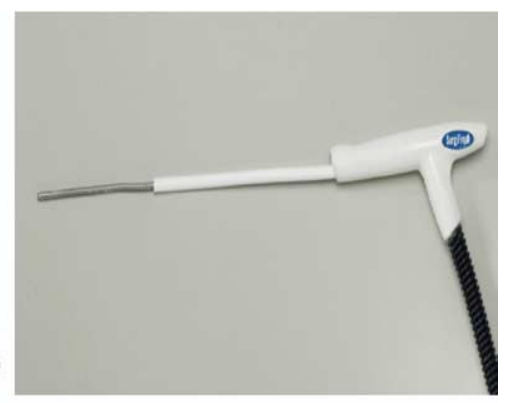

(c)

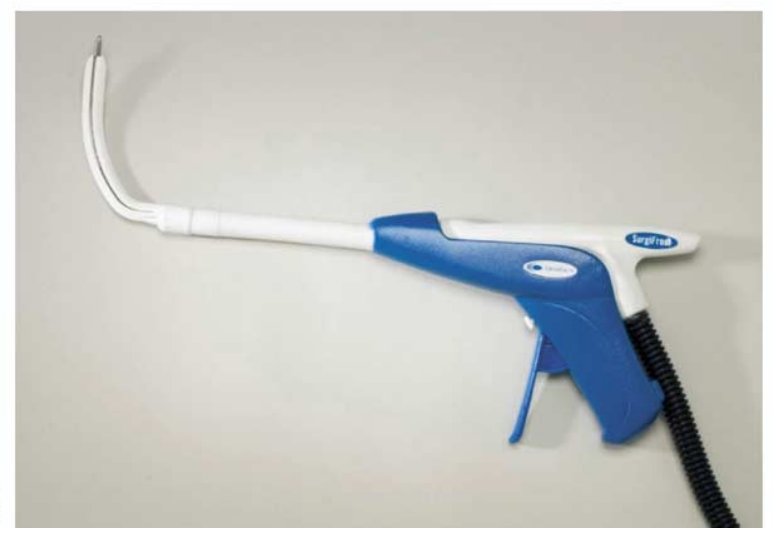

Figure 1. Clamp (A), linear probe (B), and assembled cryoclamp device (C). 

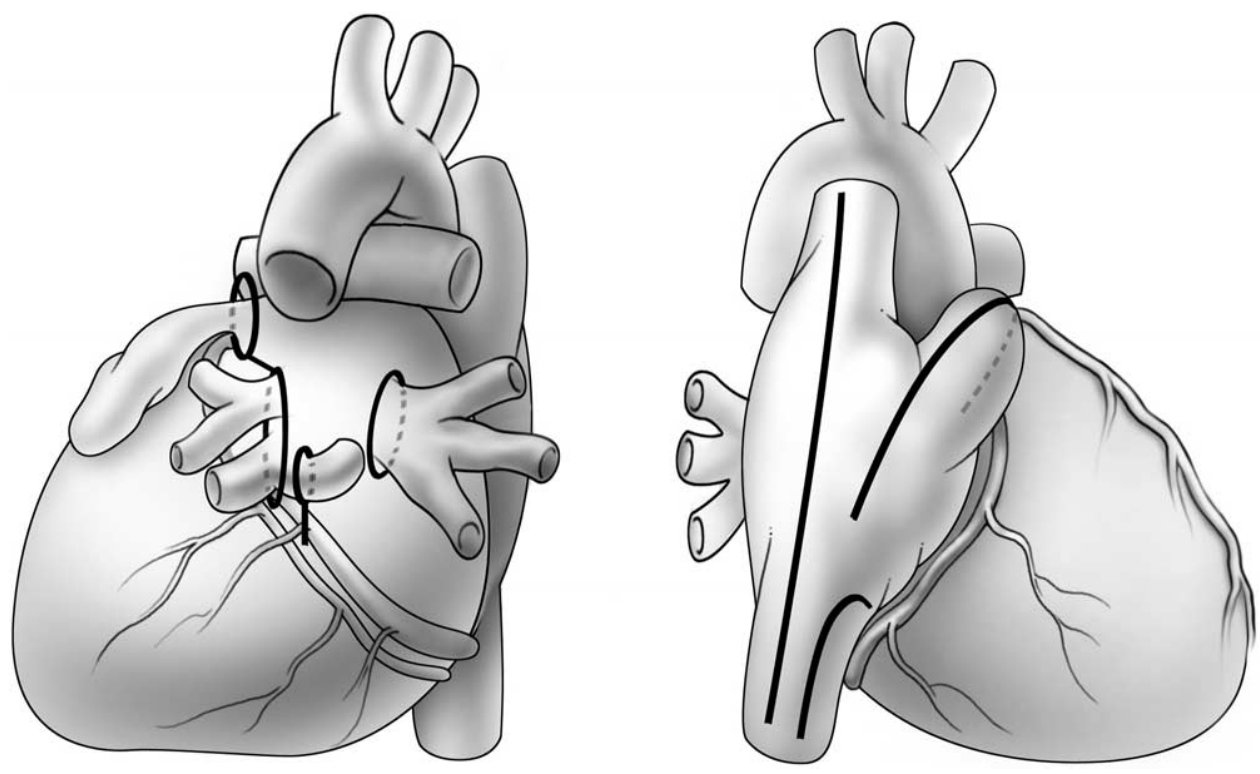

Figure 2. Diagram of a canine heart with the cryoablation lesion-set. The left side of the image demonstrates the posterior side of the heart and the lesions performed on the left atrium. The right side of the image demonstrates the anterior view of the heart and right atrium. Circles represent cryoclamp lesions; lines represent linear cryolesions.

postoperative day 5 . Acepromazine $(0.01 \mathrm{mg} / \mathrm{kg})$ and atropine $(0.05 \mathrm{mg} / \mathrm{kg})$ were administered subcutaneously for sedation; intravenous thiopental $(5 \mathrm{mg} / \mathrm{kg})$ and inhaled isoflurane were used for induction and anesthesia maintenance, respectively. Antibiotic prophylaxis was administered. A femoral arterial line and electrocardiogram were used for continuous hemodynamic assessment. A median sternotomy was performed and the pericardium was opened. Before the PV dissection was begun, a phenylephrine infusion was titrated to assist in hemodynamic control while the heart was being manipulated. The PVs were then dissected free and encir- cled with umbilical tape, and a bolus of heparin was administered intravenously $(100 \mathrm{U} / \mathrm{kg})$.

\section{Clamp Cryoablation Lesions}

A cryoclamp, which houses a $10-\mathrm{cm}$ linear cryoprobe, was used epicardially on the beating heart (Figure 1). The lesion-set consisted of an atrial cuff adjacent to the ostia of the left pulmonary veins (LPVs; Figure 2). Next, the superior and inferior right pulmonary veins (RPVs) and the base of the left atrial appendage

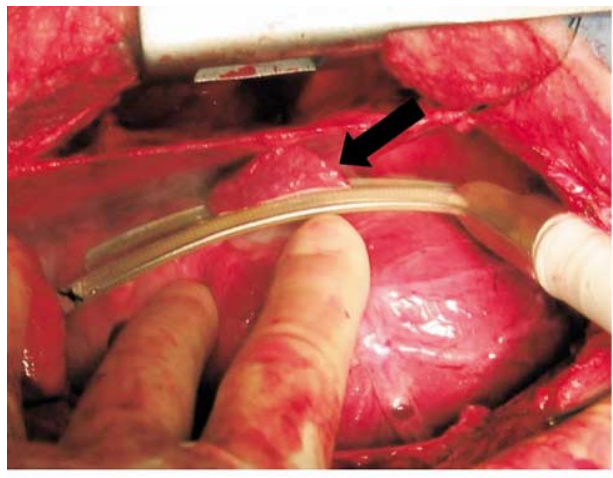

(a)

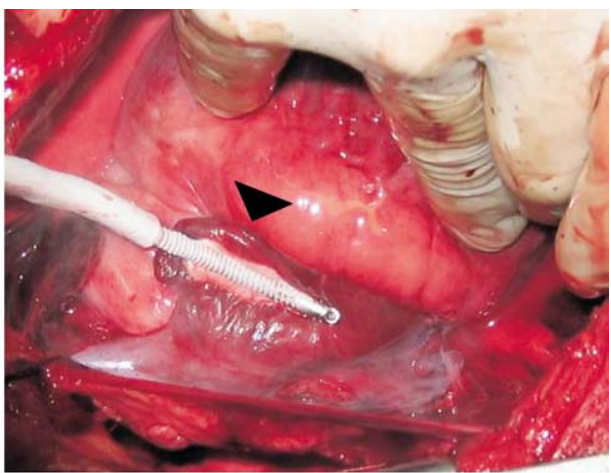

(b)

Figure 3. A, Intraoperative view of the clamp device performing a cryolesion at the base of the left atrial appendage (large black arrow). B, The cryoclamp was then disassembled and the linear probe was used to ablate the right atrial appendage (black arrow head). 
TABLE 1. Cryoclamp ablation

\begin{tabular}{|c|c|c|c|c|c|c|c|c|}
\hline Lesion & $\begin{array}{c}\text { Mean } \\
\text { temperature }{ }^{*}\left({ }^{\circ} \mathrm{C}\right)\end{array}$ & $\begin{array}{l}\text { Time to } \\
-40^{\circ} \mathrm{C}(\mathrm{s})\end{array}$ & $\begin{array}{l}\text { Electrical } \\
\text { isolationt }\end{array}$ & $\begin{array}{c}\text { Lesion } \\
\text { width }(\mathrm{cm})\end{array}$ & $\begin{array}{c}\text { Tissue } \\
\text { thickness }\end{array}$ & $\begin{array}{c}\text { Completely } \\
\text { transmural lesions }\end{array}$ & $\begin{array}{c}\text { Transmurality } \\
\text { (tissue sections) }\end{array}$ & $\begin{array}{c}\text { Transmurality } \ddagger \\
(95 \% \text { CI) }\end{array}$ \\
\hline LPV & $-48.5 \pm 2.9$ & $64.2 \pm 9.7$ & $100 \%$ & $0.5 \pm 0.1$ & $0.20 \pm 0.03$ & $83 \%(5 / 6)$ & $96 \%(23 / 24)$ & $79 \%-100 \%$ \\
\hline LAA & $-53.2 \pm 7.4$ & $50.8 \pm 13.6$ & $100 \%$ & $0.7 \pm 0.1$ & $0.33 \pm 0.06$ & $50 \%(3 / 6)$ & $70 \%(12 / 17)$ & $44 \%-90 \%$ \\
\hline SRPV & $-55.4 \pm 17.3$ & $52.6 \pm 22$ & $100 \%$ & $0.6 \pm 0.1$ & $0.14 \pm 0.02$ & $100 \%(6 / 6)$ & $100 \%(26 / 26)$ & $87 \%-100 \%$ \\
\hline IRPV & $-68.5 \pm 16.8$ & $34 \pm 18.9$ & $100 \%$ & $0.5 \pm 0.1$ & $0.15 \pm 0.03$ & $100 \%(6 / 6)$ & $100 \%(18 / 18)$ & $81 \%-100 \%$ \\
\hline
\end{tabular}

$C l$, Confidence interval; $I R P V$, inferior right pulmonary vein; $L A A$, left atrial appendage; $L P V$, left pulmonary vein; $S R P V$, superior right pulmonary vein. *Mean temperature represents the temperature reached at the end of the 20 -second dosing period. $†$ Acute and 30 -day chronic electrical isolation with maximal voltage output. $\neq$ Percentage of tissue sections with full transmurality is given along with the $95 \%$ confidence intervals.

(LAA) were cryoablated individually (Figure 3). The clamp lesions were tested for conduction block with an epicardial pacing device.

\section{Linear Cryoablation Lesions}

The clamp was then disassembled and the $10-\mathrm{cm}$ malleable probe was used to create linear lesions on both the right atrium (RA) and LA (Figures 2 and 3). All lesions were applied for a total of 3 minutes each, irrespective of the probe temperature. The lesions included a connecting lesion from the LAA to the LPV and from the LPV to the mitral annulus. For technical reasons, the RPV-toLPV connecting lesion was not performed. The right atrial lesions included a superior vena cava (SVC) to inferior vena cava (IVC) lesion, a right atrial appendage (RAA) to the IVC, and an IVC to a tricuspid valve annulus. Care was taken to avoid injury to the circumflex and right coronary arteries when performing lesions to the valve annulus. The circumflex and right coronary arteries were identified and left in situ. We did not attempt to dissect the coronary artery from the epicardial fat or retract it in any way. Great care was exercised to avoid contacting the vessels with the probe during ablation. The pericardium was then closed. A chest tube was placed into the left pleural space, and the sternum reapproximated with wires.

\section{Postoperative Care}

Postoperative care consisted of pain management with a $75-\mu \mathrm{g}$ fentanyl patch for 72 hours, oral carprofen for 5 days, and intermittent doses of subcutaneous hydromorphone as needed. Oral antibiotics were continued until postoperative day 2, when the chest tube was removed. The dogs survived for 30 days. Before the dogs were returned to the operating room for planned death and tissue harvest, postoperative TEE and MRI were performed to compare with baseline studies.

\section{Planned Death and Tissue Harvest}

The chest was reopened through the previous sternotomy and the pericardial space was reentered. The PVs and LAA were dissected free and again test-paced to assess for conduction block. A lethal dose of pentobarbital was then administered. The heart and lungs were removed en bloc. Gross inspection of the atria and PVs was made to identify lesions, inspect for mural thrombi, and to assess for PV stenosis. The entire sample was then immersed in $10 \%$ formalin for 24 hours before sectioning for histopathology.

\section{Data Acquisition}

Cryoablation. The cryoclamp consists of a 10-cm, argonbased, malleable probe (CryoCath Technology, Montreal, Quebec, Canada), which fits into a clamp device (Figure 1). Both the probe and the clamp have a thermostat, which displays real-time temperatures on the console. For the clamp lesions, once the cryoclamp was placed into position, a 20 -second dose was applied as soon as the tissue temperature reached $-40^{\circ} \mathrm{C}$. The temperatures recorded are those at the end of the 20-second dosing period (Table 1). The temperatures described for the linear lesions are the final temperatures at the end of the 3-minute ablation (Table 2).

Electrical isolation. Unipolar epicardial pacing was done with a Pacesetter (Sylmar, Calif) temporary cardiac pacemaker. A pacing lead (Medtronic Minneapolis, Minn) was used to connect the pacemaker box to a 24-inch Temporary Cardiac 2-0 Pacing Wire (Genzyme, Cambridge, Mass). Baseline pacing in all areas of the heart, including PVs, was 1 volt. Electrical isolation was defined as

TABLE 2. Right and left atrial linear cryoablation

\begin{tabular}{|c|c|c|c|c|c|c|c|c|}
\hline Lesion & $\begin{array}{c}\text { Mean } \\
\left.\text { temperature* }{ }^{\circ} \mathrm{C}\right)\end{array}$ & $\begin{array}{c}\text { Probe } \\
\text { length }(\mathrm{cm})\end{array}$ & $\begin{array}{c}\text { Lesion } \\
\text { length }(\mathrm{cm})\end{array}$ & $\begin{array}{c}\text { Lesion } \\
\text { width }(\mathrm{cm})\end{array}$ & $\begin{array}{c}\text { Tissue } \\
\text { thickness }(\mathrm{cm})\end{array}$ & $\begin{array}{c}\text { Completely } \\
\text { transmural lesions }\end{array}$ & $\begin{array}{c}\text { Transmurality (\% of } \\
\text { tissue sections) }\end{array}$ & $\begin{array}{c}\text { Transmurality† } \\
(95 \% \mathrm{CI})\end{array}$ \\
\hline RAA & $-124 \pm 24.6$ & $6.7 \pm 1.8$ & $4.8 \pm 1.2$ & $0.8 \pm 0.3$ & $0.30 \pm 0.05$ & $50 \%(3 / 6)$ & $76 \%(22 / 29)$ & $56 \%-90 \%$ \\
\hline SVC to IVC & $-113 \pm 13.0$ & $7.6 \pm 1.2$ & $3.4 \pm 0.7$ & $1.0 \pm 0.3$ & $0.18 \pm 0.05$ & $67 \%(4 / 6)$ & $91 \%(20 / 22)$ & $71 \%-99 \%$ \\
\hline Tricuspid annulus & $-135 \pm 18.6$ & $3.2 \pm 0.4$ & $1.7 \pm 0.5$ & $0.6 \pm 0.1$ & $0.25 \pm 0.11$ & $20 \%(1 / 5) \ddagger$ & $75 \%(9 / 12)$ & $43 \%-95 \%$ \\
\hline LAA to LPV & $-146 \pm 3.1$ & $2.2 \pm 0.2$ & $1.1 \pm 0.2$ & $0.8 \pm 0.1$ & $0.23 \pm 0.06$ & $100 \%(6 / 6)$ & $100 \%(10 / 10)$ & $69 \%-100 \%$ \\
\hline Coronary sinus & $-143 \pm 6.3$ & $2.3 \pm 0.3$ & $1.4 \pm 0.6$ & $0.6 \pm 0.2$ & $0.92 \pm 0.19$ & $0 \%(0 / 0)$ & $40 \% \S$ & - \\
\hline
\end{tabular}

$C l$, Confidence interval; $I V C$, inferior vena cava; $L A A$, left atrial appendage; $L P V$, left pulmonary vein; $R A A$, right atrial appendage; $S V C$, superior vena cava. *Mean temperature for linear lesions represents the temperature at the end of the 3-minute dosing period. †Percentage of tissue sections with full transmurality is given along with the $95 \%$ confidence intervals. $\ddagger$ One lesion was sectioned longitudinally. §Longitudinal sections. 


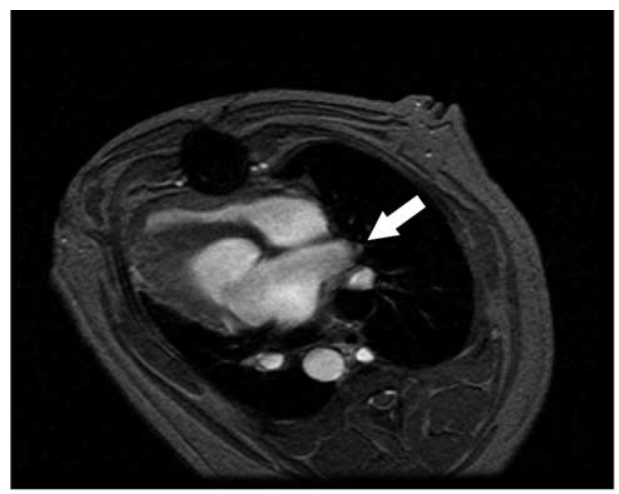

(a)

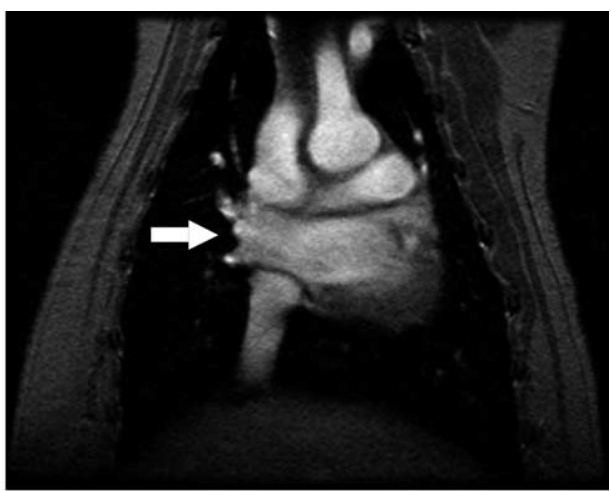

(b)

Figure 4. Magnetic resonance imaging with axial (A) and coronal (B) views of the right superior pulmonary vein (white arrow). No evidence of pulmonary vein stenosis is seen.

the inability to pace distal to the lesion with a maximal output of 10 volts.

Transesophageal echocardiography. A 5-MHz TEE (Acuson, Mountain View, Calif) was used with an XP Acuson echocardiographic system. The mitral valve was examined for anatomic abnormalities and function with 2-dimensional and color flow Doppler. The LV inflow velocities were recorded at the tips of the mitral valve leaflets with the use of a sample volume of $5 \mathrm{~mm}$. Color flow Doppler was used to align the ultrasonography beam with the direction of blood flow. The following diastolic LV inflow velocities were identified: early (E), after the beginning of diastole, and late (A), during atrial contraction. The left and right PVs were then identified with the use of 2-dimensional echocardiography and color flow Doppler. The systolic (S) and diastolic (D) velocities were recorded. When systolic velocities consisted of more than 1 peak, the highest was recorded.
Magnetic resonance imaging. MRI of the PVs was obtained with the use of a 3-Tesla scanner and V.H.3.0 software (General Electric, Milwaukee, Wis). All dogs were sedated with a single dose of pentobarbital $(30 \mathrm{mg} / \mathrm{kg}$ ) and intubated for airway control. Cine cardiac-gated MR images were obtained with an image matrix of $256 \times 192$ or $256 \times 256$ pixels, echo time (TE) 3.4 , repetition time (TR) of 8.8 , flip angle of $30^{\circ}$, and slice thickness of $6 \mathrm{~mm}$. The images were acquired in the transverse, coronal, and sagittal planes to visualize the PVs. Crosssectional images of the PVs were then used to measure vessel diameters (Figure 4).

Histopathology. After tissue harvest, the heart and lungs were immersed in $10 \%$ formalin for 24 hours. The right and left atria were splayed open, and the ostia of the PVs and LAA were identified (Figure 5). Linear cryolesions performed with the $10-\mathrm{cm}$ cryoprobe were identified and measured directly with a tape mea-

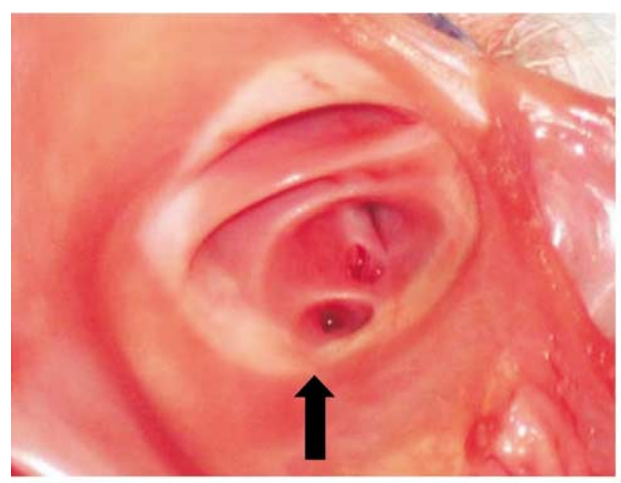

(a)

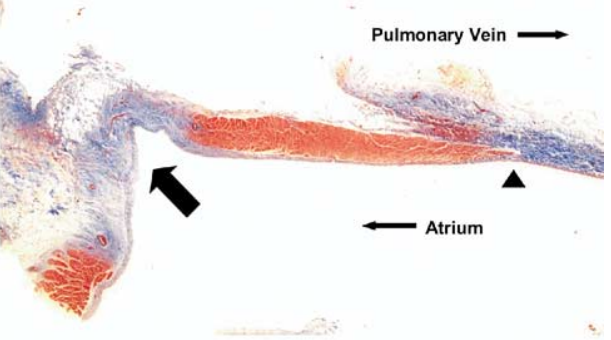

(b)

Figure 5. A, Gross picture of the right pulmonary vein as seen from within the left atrium. Large black arrow points at the cryoclamp lesion completely encircling the opening of the RPV leading to complete conduction block. B, Histologic slide of the cryoclamp lesion stained with Masson's trichrome. Large black arrow points at the transmural lesion. Black arrowhead shows the transition of left atrium to pulmonary vein. Viable cardiac muscle stains red, while connective tissue stains blue. 
TABLE 3. Assessment of pulmonary vein stenosis and left atrial function

\begin{tabular}{lccc}
\hline & Preablation & Postablation & Within-dog mean change \\
\hline $\begin{array}{c}\text { Transesophageal echocardiography } \\
\text { Transmitral flow (E/A ratio) }\end{array}$ & & & $-0.70,-0.15,-0.40 ; 0.49$ \\
Pulmonary vein velocity (cm/s) & $1.8 \pm 0.4$ & $1.6 \pm 0.3$ & $-23,-9.7,4.1 ; 0.15$ \\
RPV systolic & $37.2 \pm 14.4$ & $27.5 \pm 9.9$ & $-11,4.3,19.0 ; 0.54$ \\
RPV diastolic & $53.6 \pm 18.0$ & $57.9 \pm 20.9$ & $-12,-2.2,8.0 ; 0.63$ \\
LPV systolic & $32.5 \pm 10.7$ & $28.9 \pm 11.4$ & $-18,4.0,26 ; 0.69$ \\
LPV diastolic & $57.2 \pm 14.1$ & $57.8 \pm 19.5$ & $-8.1,-2.8,2.6 ; 0.22$ \\
Magnetic resonance imaging & & & $-4.0,-1.4,1.3 ; 0.22$ \\
Vessel diameter (mm) & & & $-3.5,-1.0,1.4 ; 0.30$
\end{tabular}

E/A ratio, Early diastolic filling/late diastolic filling ratio during atrial contraction; ILPV, inferior left pulmonary vein; IRPV, inferior right pulmonary vein; $L P V$, left pulmonary vein; $R P V$, right pulmonary vein; $S R P V$, superior right pulmonary vein. *Within-dog mean change with $95 \%$ confidence intervals (lower, estimate, upper; $P$ value).

surer. Both clamp lesions and linear epicardial lesions were excised from the heart as a single intact lesion. The circular clamp lesions were cut open so as to convert a circular lesion to a linear lesion by cutting open the vein along its length. All lesions were then cut into 2- to 3-mm cross sections and placed on the embedding cartridge. The entire length of the lesion was used, which in some cases required more than 1 cartridge. The sections were then placed in the cartridge in sequential order. The tissue sections were stained with both hematoxylin and eosin, and Masson's trichrome and were interpreted by a veterinary pathologist. The results are expressed as the percentage of tissue sections with fully transmural lesions.

\section{Statistical Analysis}

Continuous variables are reported as mean \pm SD. A 2-tailed paired Student $\mathrm{t}$ test was performed when comparing preoperative and postoperative MRI and TEE results. Estimates of rates and 95\% confidence intervals, and of mean within-dog changes in variables and $95 \%$ confidence intervals of these changes, are given.

\section{Results}

\section{Operative Results}

All PV and LAA lesions were made with a single application of the cryoclamp (Table 1). Electrical isolation was found in both acute and chronic lesions. The clamp device allowed for complete encirclement of all left PVs. The LA appendage was clamped at its base and ablated (Figure 3). The right PVs were clamped individually.

For the linear lesions, mean probe length used for the RA and LA lesions was $6.0 \pm 2.5 \mathrm{~cm}$ and $2.8 \pm 1.1 \mathrm{~cm}$, respectively. Mean final temperatures for these lesions were $-124.5^{\circ} \mathrm{C} \pm 20.4^{\circ} \mathrm{C}$ and $-139.2^{\circ} \mathrm{C} \pm 16.2^{\circ} \mathrm{C}$, respectively. Longer segments of probe exposed to the tissue lead to warmer temperatures at the end of the dosing period (Table 2).

All dogs survived the 30-day study period.

\section{MRI}

Cine MRI of the PVs was obtained in coronal, axial, and sagittal views (Figure 4). Preoperative and postoperative images were then compared to evaluate for PV stenosis. None of the postoperative images identified a stenotic lesion. In addition, measurements of the preoperative and postoperative images did not demonstrate significant changes in PV diameters (Table 3).

\section{TEE}

The same investigator performed all TEE studies. No significant change in LA systolic function (E/A ratio) was found: $\mathrm{E} / \mathrm{A}$ at baseline vs sacrifice, $1.78 \pm 0.4$ vs $1.62 \pm$ $0.3, P=.49$. The atrial systolic velocity was comparable between the 2 groups (A wave preablation, $46.7 \pm 13.2$ $\mathrm{cm} / \mathrm{s}$ vs A wave postablation, $36.7 \pm 6.8 \mathrm{~cm} / \mathrm{s} ; P=.25)$. There were no significant changes on PV flow velocities between preablation and postablation studies (Table 3).

\section{Postmortem Analysis}

Visual inspection of the clamp lesions to the PV and LAA did not demonstrate stenosis or endoluminal thrombi (Figure 5). Lesion width ranged from 0.4 to $0.7 \mathrm{~cm}$. All PV tissue sections demonstrated $100 \%$ transmurality, whereas $70 \%$ of LAA sections were fully transmural (Table 1). All linear lesions were readily identified on gross inspection. Linear lesion width ranged from 0.5 to $1.6 \mathrm{~cm}$ (Table 2). Final pathologic examination demonstrated full transmurality in $84 \%$ of the tissue sections (Figure 6). Figure 6 demonstrates examples of nontransmural linear cryolesions. Linear lesions performed from the inferior LPV across the coronary sinus (CS) to the mitral annulus demonstrated segments of full transmurality in 4 of 6 dogs (Figure 7). The lesions to the CS were sectioned parallel to the lesion so as 


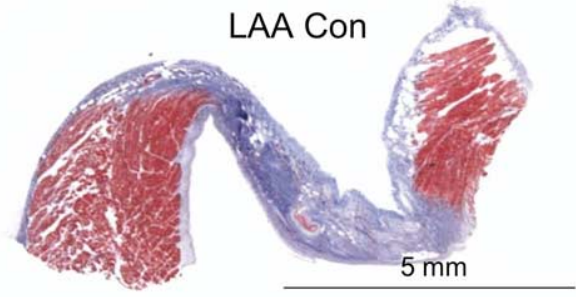

(a)

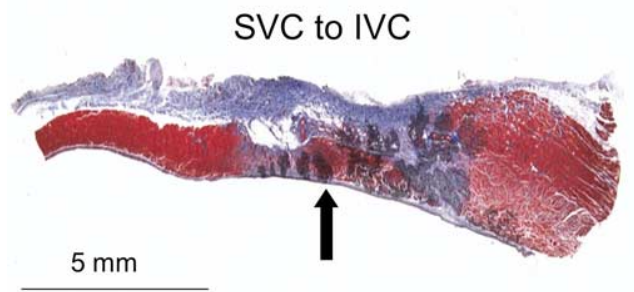

(c)

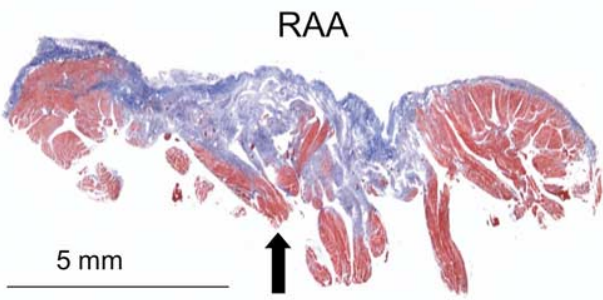

(b)

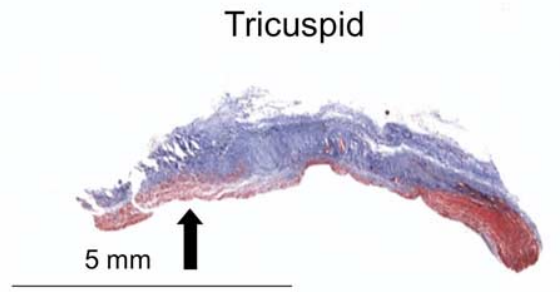

(d)

Figure 6. Histologic cross sections of linear epicardial lesions performed with the $\mathbf{1 0} \mathrm{cm}$ malleable probe on both right and left atria. Tissue sections are stained with Masson's trichrome. Blue color demonstrates fibrotic scar tissue, and red stain shows viable myocardium. Solid arrow points to viable myocardium within the lesion. A, Left atrial appendage to left pulmonary veins connecting lesion (LAA con) demonstrating complete transmurality. $B$, Right atrial appendage lesion (RAA) demonstrating areas of viable myocardium in the trabeculated regions of the appendage. C, Superior vena cava to inferior vena cava lesion (SVC to IVC) demonstrating a region at the mid-portion of the lesion with viable myocardium. D, Tricuspid flutter lesion with subendocardial sparing. Arrow points to the nontransmural segment.

to clearly define the depth of penetration below the CS. With this type of sectioning, it is conceivable that the slide may not represent an equal plane along the lesion; therefore, it may not demonstrate full-thickness transmurality, which may be a limitation to the CS lesion analysis. The tricuspid annulus lesions were cut into cross sections, which may be a more sensitive way of determining lesion transmurality.

\section{Discussion}

Previous experience with cryoablation technology has been limited for epicardial ablation on beating hearts. ${ }^{9}$ This limitation may be attributable to the heat-sink effect, which may prevent sufficient cooling for the creation of transmural lesions. This new ablation technology uses argon gas, leading to tissue temperatures as low as $-160^{\circ} \mathrm{C}$, which aids in combating the heat-sink effect. In addition, the use of a clamp device further decreases the heat sink by temporarily occluding blood flow. After a single cryoablative dose, the clamp device was able to effectively achieve electrical isolation in both the PV and LAA. After a 30-day survival period, we did not find significant differences in preopera- tive and postoperative MRI PV diameters to suggest PV stenosis as a result of the clamp lesions. In addition, PV flow peak velocities and transmitral flow velocities measured by TEE did not show evidence of PV stenosis or LA dysfunction. However, we do acknowledge that our sample size was small and the power to detect small differences, if present, was therefore low.

The histologic results of the clamp lesions are comparable with other animal studies in which bipolar radiofrequency was used. ${ }^{11,12}$ Histologic assessment of clamp cryolesions demonstrated nearly $100 \%$ transmurality in PV clamp lesions, with the exception of the LAA lesions, which had 5 of 17 (29.4\%) tissue sections with nontransmural lesions. These tissue sections demonstrated thin regions of subendocardial sparing, particularly in the thicker trabeculated regions of the LAA. Despite this finding, the LAA demonstrated complete conduction block on test pacing (Table 1). However, even though test pacing was performed, we do acknowledge that we cannot prove for certain that we had local capture on test pacing, as we did not attempt to record electrograms in the isolated LAA or PV. One of the important 
(a)

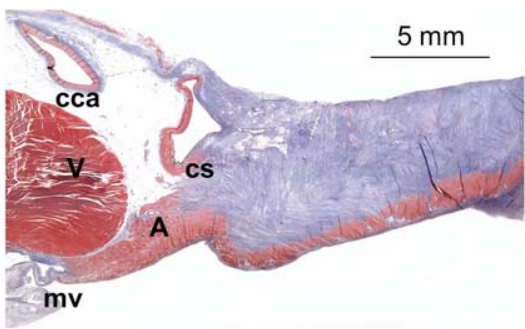

(b)

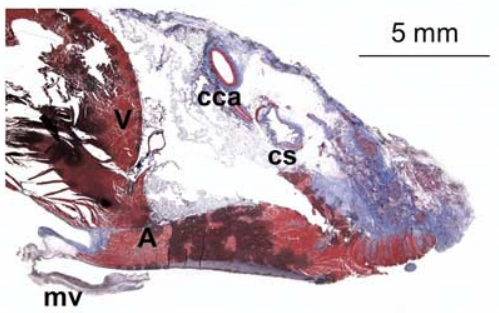

(c)

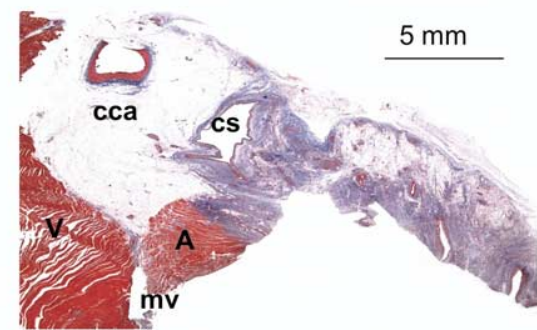

(d)

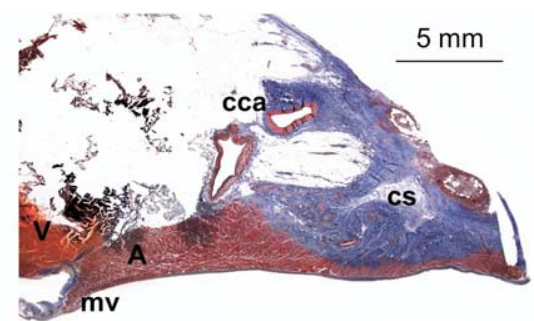

(e)

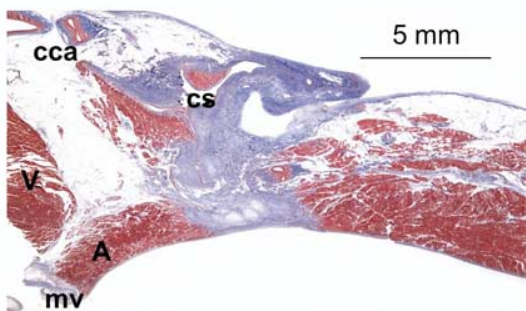

(f)

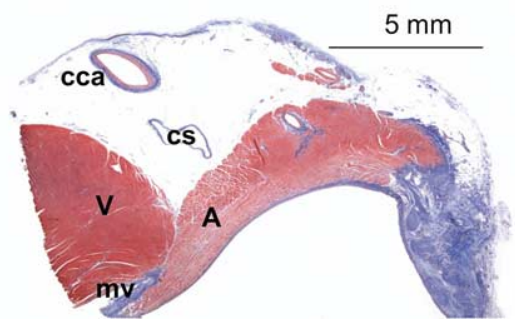

Figure 7. Histologic longitudinal sections of cryolesions extending from the left inferior pulmonary vein across the coronary sinus and mitral valve annulus. Tissue sections are stained with Masson's trichrome. Blue color demonstrates fibrotic scar tissue, and red stain shows viable myocardium. A, Nontransmural lesion showing fibrotic replacement along the epicardium, with subendocardial sparing. Partial ablation of the CS. B, Transmurality seen only in the right-most portion of the lesion, including the CS. Atrial tissue below the investing fat has been completely spared. Black areas represent artifact. C, Transmural ablation of nearly the entire lesion, including the CS. Atrial tissue below the CS has been spared. D, Nontransmural ablation of the right portion of the lesion and the CS. E, Transmural ablation of the CS and the tissue below the CS. Atrial tissue to the right and left of the CS has been spared completely. F, Transmural ablation of the right portion of the slide. The CS and atrial tissue below the investing fat have been spared completely. A, Atrium; CCA, circumflex coronary artery; $C S$, coronary sinus; $M V$, mitral valve; $V$, ventricle.

principles in performing ablative procedures for $\mathrm{AF}$ is the creation of lesions that are transmural. ${ }^{13}$ While the Cox maze III assures $100 \%$ transmurality with cut-and-sew lesions, only bipolar radiofrequency is reliable in ensuring $100 \%$ transmurality. ${ }^{12}$ Endocardial cryoablation on the arrested heart provides the most optimum condition for transmural lesion with a smooth endocardial surface, and without heat dissipation from the intracardiac blood flow. Epicardial ablation on the beating heart, however, introduces the heat sink of intracardiac blood flow; in addition to epicardial fat, which prevents good tissue contact with the probe. ${ }^{14}$ Although these thin subendocardial regions of cardiac tissue were spared, the relevance of this is unknown, as these lesions continued to demonstrate complete conduction block.

A similar phenomenon was noted in a dog study with the use of microwave energy to create a single circular lesion to isolate the PVs. ${ }^{10}$ The investigators were able to achieve nearly $100 \%$ electrical isolation of the PVs in both acute and 3 -week survival dog models. On histologic analysis, however, a mean of $33 \%$ transmurality was seen in the acute lesions, while the 3-week survival lesions demonstrate a mean $66 \%$ transmurality. The investigators concluded that lesions leading to electrical isolation are an effective means of blocking atrial conduction, despite being histologically incomplete. Linear lesions to both right and left atria also did not lead to $100 \%$ transmurality in all tissue sections. Areas of thickened tissue such as the RAA lead to the highest failure rates, and thinner tissue had more transmural tissue sections (SVC to IVC). While tissue thickness likely played a factor in these results, the length of the probe exposed to the tissue also led to warmer temperatures, and therefore decreased its efficacy, leading to failures (Table 2). 
Short lesions with thin tissue such as the LAA to LPV lesions led to $100 \%$ transmurality. Furthermore, although 4 of $6 \mathrm{LPV}$ to mitral annulus lesions demonstrated areas of complete transmurality, none of these lesions demonstrated full transmurality throughout the entire length of the lesion. Cardiac tissue underneath the CS moving toward the annulus remained viable in all instances. Reasons for this failure include the presence of thick regions of epicardial fat in the interatrial groove, close proximity of the circumflex coronary artery preventing adequate probe alignment, and technical limitations of the prototype probe. To avoid injury to the circumflex artery, we were careful to avoid any contact with the vessel, which prevented adequate position to ablate the region of cardiac tissue underneath the CS. In addition, the tip of this prototype probe had nearly a half-centimeter region that did not cool as well as the rest of the probe. We believe this played a factor in preventing the creation of fully transmural lesions in this anatomic region. Modifications have since been made to avoid this limitation.

As with most animal studies, data from this study cannot be directly extrapolated to the human heart, whose tissue thickness and fat content are different. Although it appears that this ablation device was able to produce transmural lesions in this dog model, we cannot extrapolate this information to predict the degree of transmurality achievable in a human heart, which may be affected by chronic conditions such as rheumatic heart disease and long-standing mitral regurgitation. Most, but not all, lesions of the Cox maze III procedure were performed in this study. The LPV to RPV connecting lesion was not performed because of the anatomic proximity of the inferior pulmonary veins. Such close proximity may have led to an inability to differentiate the clamp lesions from the linear connecting lesion.

In conclusion, recent advances in technology have led to the creation of ablative devices that can replace the cut-andsew technique used in the Cox maze III procedure. Cryoclamp ablation of the PVs and LAA in this canine model resulted in lesions with complete conduction block. Linear epicardial cryoablation using the $10-\mathrm{cm}$ linear probe demonstrated transmurality in $85 \%$ of the tissue sections. Thus, compared with the CC device, linear epicardial cryoablation was not as effective at producing consistent transmural lesions.

This novel cryoablation probe and clamp device may offer yet another option for cardiac surgeons performing ablative procedures to treat AF. With this prototype, the clamp and probe easily disassemble and reassemble, allowing the surgeon to perform both clamp ablations and linear ablations with a single instrument. Future prototypes of this cryothermy technology may increase further the ability to perform transmural lesions via an epicardial approach on a beating heart, which may then continue to improve minimally invasive approaches using cryothermy.

\section{References}

1. Ryder KM, Benjamin EJ. Epidemiology and significance of atrial fibrillation. Am J Cardiol. 1999;84(9A):131R-8R.

2. Kannel WB, Wolf PA, Benjamin EJ, Levy D. Prevalence, incidence, prognosis, and predisposing conditions for atrial fibrillation: populationbased estimates. Am J Cardiol. 1998;82:2N-9N.

3. Cox JL, Schuessler RB, D'Agostino HJ, Stone CM, Chang B, Cain ME, et al. The surgical treatment of atrial fibrillation III. Development of a definitive surgical procedure. J Thorac Cardiovasc Surg. 1991; 101:569-89.

4. Prasad SM, Maniar HS, Camillo CJ, Schuessler RB, Boineau JP, Sundt TM, et al. The Cox maze III procedure for atrial fibrillation: long-term efficacy in patients undergoing lone versus concomitant procedures. J Thorac Cardiovasc Surg. 2003;126:1822-8.

5. Cox JL, Schuessler RB, Boineau JP. The development of the maze procedure for the surgical treatment of atrial fibrillation. Semin Thorac Cardiovasc Surg. 2000;12:2-14.

6. Lustgarten DL, Keane D, Ruskin J. Cryothermal ablation:mechanism of tissue injury and current experience in the treatment of tachyarrhythmias. Prog Cardiovasc Dis. 1999;41:481-98.

7. Doll N, Kiaii BB, Fabricius AM, Bucerius J, Kornherr P, Krakor R, et al. Intraoperative left atrial ablation (for atrial fibrillation) using a new argon cryocatheter: early clinical experience. Ann Thorac Surg. 2003;76:1711-5.

8. Mack CA, Milla F, Ko W, Girardi LN, Lee LY, Tortolani AJ, et al. Surgical treatment of atrial fibrillation using argon-based cryoablation during concomitant cardiac procedures. Circulation. 2005;112(Suppl I): I1-6.

9. Lee R, Nitta T, Schuessler RB, Johnson DC, Boineau JP, Cox JL. The closed heart MAZE: a nonbypass surgical technique. Ann Thorac Surg. 1999;67:1696-1702.

10. van Brakel TJ, Bolotin G, Salleng KJ, Nifong LW, Allessie MA, Chitwood WR, et al. Evaluation of epicardial microwave ablation lesions: histology versus electrophysiology. Ann Thorac Surg. 2004; 78:1397-402.

11. Bonanomi G, Schwartzman D, Francischelli D, Hebsgaard K, Zenati MA. A new device for beating heart bipolar radiofrequency atrial ablation. J Thorac Cardiovasc Surg. 2003;126:1859-66.

12. Prasad SM, Maniar HS, Diodato MD, Schuessler RB, Damiano RJ. Physiological consequences of bipolar radiofrequency energy on the atria and pulmonary veins: a chronic animal study. Ann Thorac Surg. 2003;76:836-42.

13. Melo JQ, Santiago T, Gouveia RH, Martins AP. Atrial Ablation for the Surgical Treatment of Atrial Fibrillation:Principles and Limitations. J Card Surg. 2004;19:207-10.

14. Williams MR, Garrido M, Oz MC, Argenziano M. Alternative energy sources for surgical atrial ablation. J Card Surg. 2004;19:201-6. 